\title{
Analysis on Spatio-temporal Characteristics of Wintertime Planetary Wave in the Northern Hemisphere Based on 2D FFT
}

\author{
Xiuhong Wang ${ }^{1}$ and Weidong $\mathrm{Yu}^{2}$ \\ ${ }^{1}$ Information Retrieval Office, Jiangsu University, NO.301 Xuefu Road, Zhenjiang, China \\ ${ }^{2}$ Lab of Marine Science and Numerical modeling, First Institute of Oceanography, SOA, China \\ Lib510@uj.s.edu.cn, wdyuafio.org.cn
}

\begin{abstract}
To describe spatial and temporal characteristics of the activities of wintertime planetary waves in the northern hemisphere, their numbers and periods were precisely calculated, based on NCAR/NCEP reanalysis data. The objective variables include sea level pressure (SLP) and anomaly stream function at $850 \mathrm{hPa}, 500 \mathrm{hPa}$ and $200 \mathrm{hPa}$. 2D FFT and spectral analysis reveal that: (1) The wave numbers 1 and 2 dominate the perturbation pattern at $70^{\circ}-80$ ${ }^{\circ} \mathrm{N}$ zonal belt. (2) The wave numbers 1,2 and 3 dominate at $60^{\circ}-70^{\circ} \mathrm{N}$ zonal belt. (3) The wave numbers $1-4$ dominate at $50^{\circ}-60^{\circ} \mathrm{N}$ zonal belt. The results accord fairly well with Rossby's classical trough formula and are of potential use for understanding the northern hemisphere large-scale oscillations.
\end{abstract}

Keywords: Planetary wave, Large-scale oscillations, Northern hemisphere, Wave number.

\section{Introduction}

According to Rossby's [1] previous work on the relationship between variations in the intensity of the zonal circulation of the atmosphere and the displacements of the semi-permanent centers of action, it is well known that the planetary waves have significant impact on the troposphere circulation. Based on the trough formula, as is often called, Rossby roughly calculated the number of the long stationary waves and their wavelength.

Recent studies reveal that the northern hemisphere climate takes on some kinds of oscillations, including the North Atlantic Oscillation (NAO), the Arctic Oscillation (AO) [2] and the Pacific North American pattern (PNA). These features have close relationship with the planetary wave activities. Cavalieri and Häkkinen [3] reported the variability of SLP planetary waves and related these planetary-scale variations with some changes of climate observed in the Arctic over the last fifty years. Yu [4] proposed a stationary wave- 2 frame to relate the NAO, AO and NPO on the basis of 
Hoskins' great circle theory. Here the analysis to the higher levels in the troposphere is further extended to demonstrate the planetary wave activities and to show their climate impact.

\section{Analysis and Results}

The monthly SLP and wind data at $850 \mathrm{hPa}, 500 \mathrm{hPa}$ and $200 \mathrm{hPa}$ levels from the NCAR/NCEP Reanalysis Data [5] are used here. Their anomalies are deduced by extracting the corresponding climatologies. The time covers from 1948 to 2003. To examine the characteristics of the planetary-scale wave, only the rotational part of the wind field is kept. It is conducted by decomposing the wind field into non-divergent part $\vec{V}_{\psi}$ plus an irrotational part $\vec{V}_{\phi}$ according to the Helmholtz theorem [6]. Thus the stream function $\psi$ is introduced as:

$$
\varsigma=\nabla^{2} \psi
$$

where the $\checkmark$ is the vorticity. The global stream function corresponding to the rotational part of the wind anomaly is acquired through Eq.(1) with the aid of the Fishpack program package [7]. Then the following analysis is conducted on the basis of SLP and the stream functions at $850 \mathrm{hPa}, 500 \mathrm{hPa}$ and $200 \mathrm{hPa}$ levels.

Table 1. Fraction of variance (in percentage) accounted by different wave structures

\begin{tabular}{ccccccc}
\hline Field & Latitude & Wave 1 & Wave 2 & Wave 3 & Wave 4 & Wave 5 \\
\hline SLP & $70^{\circ}-80^{\circ} \mathrm{N}$ & 71.086 & 19.787 & 5.0084 & 2.0065 & 0.53583 \\
& $60^{\circ}-70^{\circ} \mathrm{N}$ & 44.529 & 34.572 & 9.8977 & 6.943 & 1.8271 \\
& $50^{\circ}-60^{\circ} \mathrm{N}$ & 26.601 & 37.112 & 16.061 & 11.722 & 4.3615 \\
& $70^{\circ}-80^{\circ} \mathrm{N}$ & 62.705 & 29.641 & 5.047 & 2.0109 & 0.30322 \\
$\begin{array}{c}850 \mathrm{hPa} \\
\text { stream function }\end{array}$ & $60^{\circ}-70^{\circ} \mathrm{N}$ & 34.058 & 40.701 & 15.4 & 7.3467 & 1.3215 \\
& $50^{\circ}-60^{\circ} \mathrm{N}$ & 29.592 & 29.31 & 20.663 & 14.185 & 3.7139 \\
$\begin{array}{c}500 \mathrm{hPa} \\
\text { stream function }\end{array}$ & $70^{\circ}-80^{\circ} \mathrm{N}$ & 52.222 & 38.733 & 6.0772 & 2.4429 & 0.33537 \\
& $50^{\circ}-60^{\circ} \mathrm{N}$ & 25.804 & 25.823 & 25.778 & 16.562 & 3.8251 \\
& $70^{\circ}-80^{\circ} \mathrm{N}$ & 60.842 & 33.641 & 4.5788 & 0.79062 & 0.10893 \\
200hPa & $60^{\circ}-70^{\circ} \mathrm{N}$ & 32.834 & 44.366 & 17.247 & 4.6042 & 0.65593 \\
stream function & $50^{\circ}-60^{\circ} \mathrm{N}$ & 25.658 & 30.039 & 25.198 & 14.434 & 3.2481 \\
\hline
\end{tabular}


Furthermore, the analysis focuses on three ten-degree latitude bands from $50^{\circ} \mathrm{N}$ to $80^{\circ}$ $\mathrm{N}$ latitude, with the January being used as the representative of the wintertime.

We chose $200 \mathrm{hPa}, 500 \mathrm{hPa}$ and $850 \mathrm{hPa}$ layers as the representatives of the upper, middle and lower troposphere. The temporal and spatial structure of the planetaryscale wave revealed by the 2D FFT is shown in Fig.1 respectively for the anomalous SLP and the stream functions at upper, middle and lower troposphere. Also the fraction of variance accounted by different waves is shown in Table 1. As for the case of SLP, the wave structure shows different characteristics in three bands. For the $70^{\circ}$ $80^{\circ} \mathrm{N}$ band, the significant fraction of the variance in SLP is carried by wave 1 , which accounts for over $71 \%$ of the total variance. The energy in shorter waves increases significantly with the decrease of the latitude. The wave 2 in $60^{\circ}-70^{\circ} \mathrm{N}$ band and the wave 3 in $50^{\circ}-60^{\circ} \mathrm{N}$ band vary significantly, and they account for over $19 \%$ and $5 \%$ of the total variance respectively. This tendency also exists in the stream functions, which has the generally similar energy distribution in the wave number space with the intensity of variation increasing from $850 \mathrm{hPa}$ to $200 \mathrm{hPa}$ level. As for the stream functions, the structures of waves $1-2$ in $70^{\circ}-80^{\circ} \mathrm{N}$ band, waves $1-3$ in $60^{\circ}-70^{\circ} \mathrm{N}$ band and waves $1-4$ in $50^{\circ}-60^{\circ} \mathrm{N}$ band dominate the variance and explain over $90 \%$ of the total variance. From the lower level to the upper level of the troposphere, the perturbation has the similar pattern in the three bands. The result accords well with the qualitative estimate of the stationary wave length given by Rossby's trough formula.

The 2D FFT gives further information on the temporal characteristics of the spatial structure mentioned above. Waves of different length scale have different characteristics of the time evolution. [3] pointed out that the phases of waves 1 and 2 in $70^{\circ}-80^{\circ} \mathrm{N}$ band have significant peaks at 3.6, 5.6 and 12.5 years for SLP field. The present analysis focuses on the amplitude of the variation but not on the phase. However, the temporal characteristic can also be seen from Fig. 1. The powers of waves 1,2 and 3 in $50^{\circ}-80^{\circ} \mathrm{N}$ band show concentration peaks at 2.9-, 3.6-, 4.4-, 5.6-, 6.9-, 12.5-, near 14-, near 33-, and near 60-year periods both for SLP and for stream functions. The 3.6-year period is likely related to atmospheric circulation changes with El Nino [8]. The 5.6-year period is probably associated with the variability in Arctic sea ice extent [9]. The reason for the decadal and the interdecadal signals is not clear and needs further exploration. It should be noted that the 5.6-year period is most significantly associated with the wave 2 structure in $60^{\circ}-70^{\circ} \mathrm{N}$ band, while the decadal signal is most significantly associated with the wave 1 structure in all the three bands and with the wave 3 structure just in $50^{\circ}-60^{\circ}$ $\mathrm{N}$ band. Except for the decadal signal, the interannual (here are 2.9-, 3.6- and 6.9year periods) signal is also very significantly associated with wave 1 structure in high latitude bands. This may cast some light on their physical interpretation. ENSO has its global influence through the Rossby wave propagation and dispersion on the sphere and thus the signal can be detected at all the three bands. The Arctic 


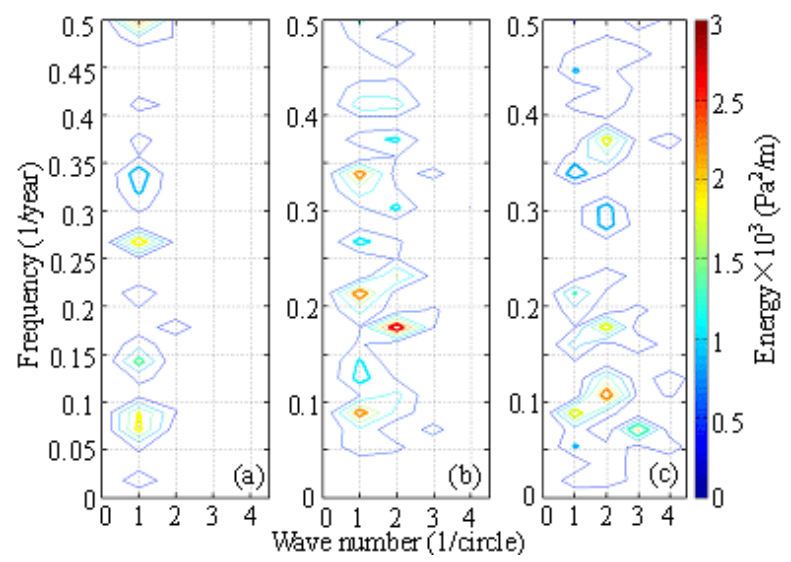

( I )

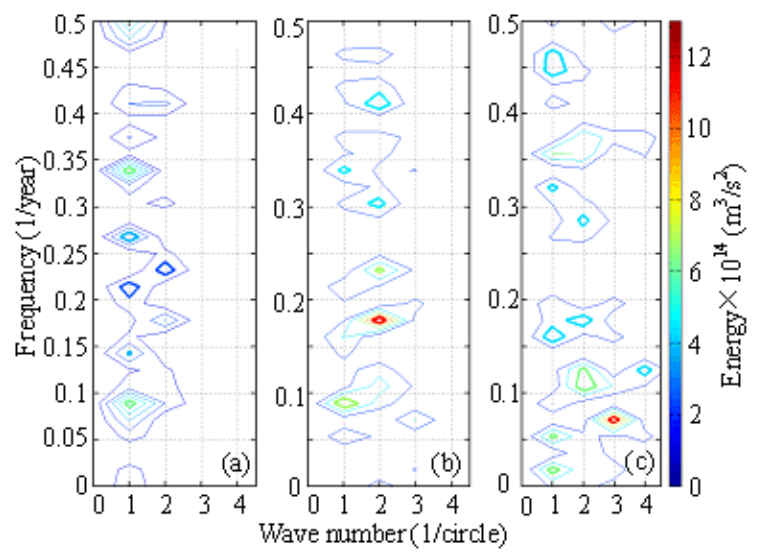

( II )

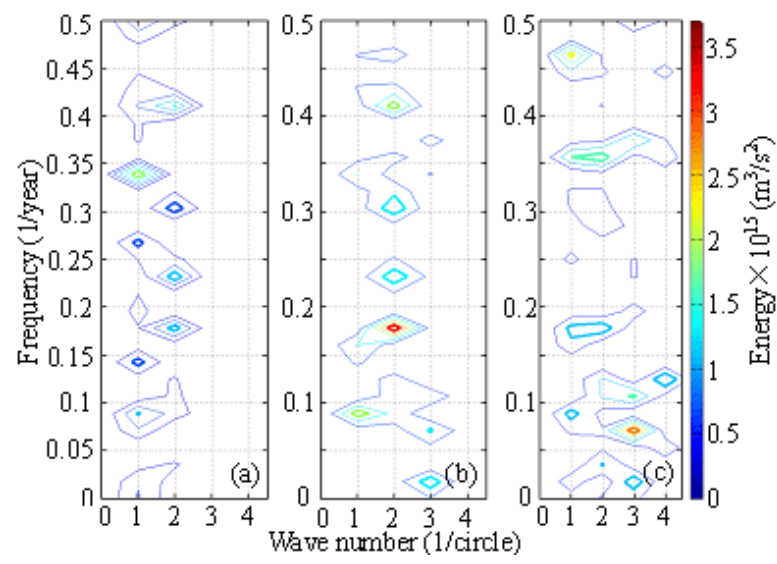

(III)

Fig. 1. 2D FFT of the perturbed SLP and stream function 


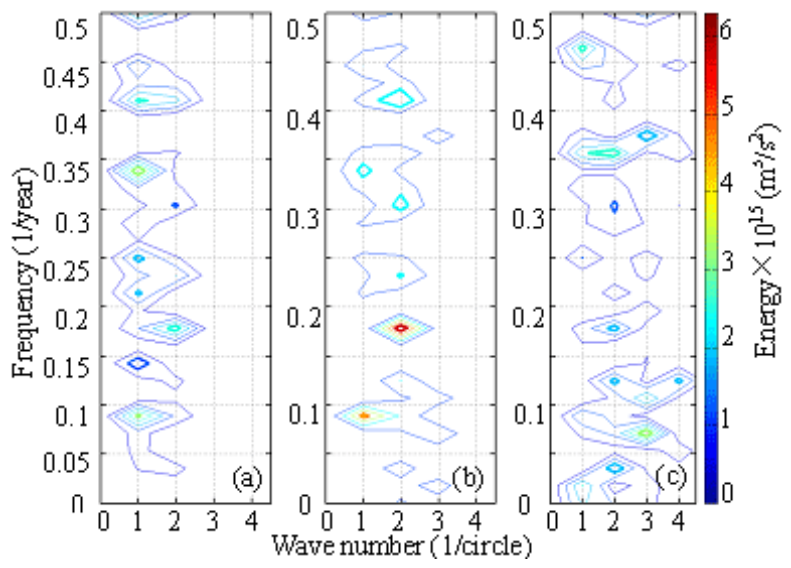

(IV)

Fig. 1. (Continued)

sea ice extent variation can cause the large-scale perturbation, which directly influences the high latitude region because the perturbed long Rossby wave propagates in the zonal and northward direction but not in southward direction according to Hoskins' great circle theory [10].

( I ) a. SLP in $70^{\circ}-80^{\circ} \mathrm{N}$ band; b. SLP in $60^{\circ}-70^{\circ} \mathrm{N}$ band; c. SLP in $50^{\circ}-60^{\circ} \mathrm{N}$ band;

( II ) a. $850 \mathrm{hPa}$ stream function in $70^{\circ}-80^{\circ} \mathrm{N}$ band; b. $850 \mathrm{hPa}$ stream function in $60^{\circ}-70^{\circ} \mathrm{N}$ band; c $850 \mathrm{hPa}$ stream function in $50^{\circ}-60^{\circ} \mathrm{N}$ band;

(III) a. $500 \mathrm{hPa}$ stream function in $70^{\circ}-80^{\circ} \mathrm{N}$ band; b. $500 \mathrm{hPa}$ stream function in $60^{\circ}-70^{\circ} \mathrm{N}$ band; c. $500 \mathrm{hPa}$ stream function in $50^{\circ}-60^{\circ} \mathrm{N}$ band;

(IV) a. $200 \mathrm{hPa}$ stream function in $70^{\circ}-80^{\circ} \mathrm{N}$ band; b. $200 \mathrm{hPa}$ stream function in $60^{\circ}-70^{\circ} \mathrm{N}$ band; c. $200 \mathrm{hPa}$ stream function in $50^{\circ}-60^{\circ} \mathrm{N}$ band

The spatial-temporal structure is further explored by power spectrum analysis with the time series (1948-2003) of the variances accounting for waves 1-4, as shown in Fig. 2. The fraction of variance is calculated with the FFT of the anomalous quantity subtracted from the zonal average for each calendar January. The time evolution further supports the above conclusion of the wave structure at three latitude bands. It has been known from Table 1 that waves 1 and 2 dominate the variance for $60^{\circ}-80^{\circ} \mathrm{N}$ band. An interesting point here is that the waves 1 and 2 in $60^{\circ}-80^{\circ} \mathrm{N}$ band vary out of phase, i.e. they alternatively dominate the variance among most of years and only coexist in few years. The out-of-phase evolution of different wave structures exists from the surface to the upper troposphere level. Also the overall wave structures keep well vertically. 

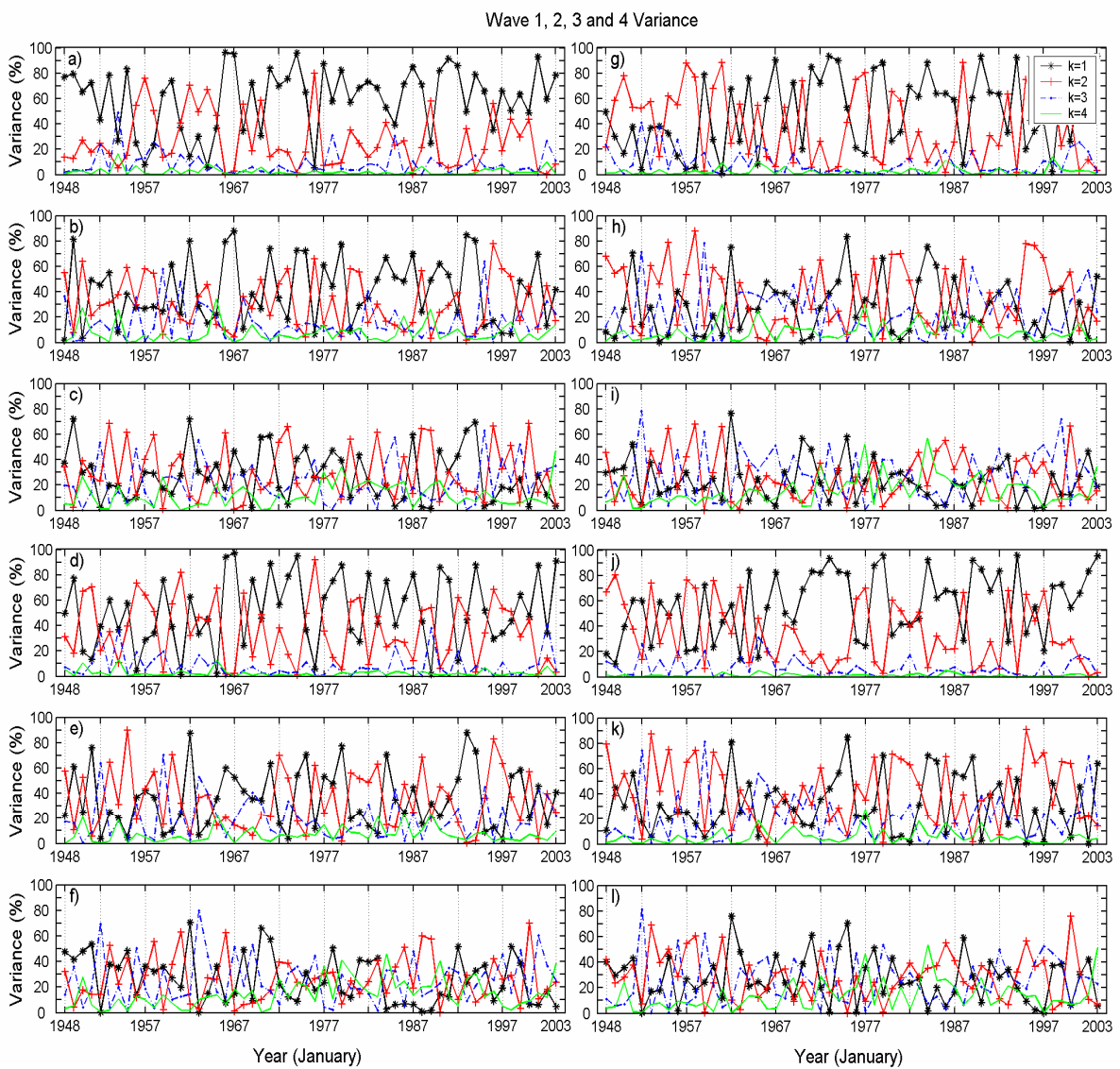

Fig. 2. Time series of the fraction of variance accounted by different wave structure

\section{Discussion and Conclusion}

It is anticipated from Rossby's pioneering work that the stationary long Rossby wave stands in the northern hemisphere and has close relationship to the intensity of the semi-permanent action center. Based on the NCAR/NCEP reanalysis data, the idea is fully examined and it is shown from the diagnosis that the variation of the perturbed SLP and stream functions from lower to upper troposphere has rather systematic structure. Waves 1-4 dominate the variance pattern at $50^{\circ}-60^{\circ} \mathrm{N}$ band, while waves 1 3 and $1-2$ dominate it in $60^{\circ}-70^{\circ} \mathrm{N}$ band and in $70^{\circ}-80^{\circ} \mathrm{N}$ band respectively. The significant wave structure accounts for over $90 \%$ of the total variance.

a. SLP in $70^{\circ}-80^{\circ} \mathrm{N}$ band; b. SLP in $60^{\circ}-70^{\circ} \mathrm{N}$ band; c. SLP in $50^{\circ}-60^{\circ} \mathrm{N}$ band;

d. $850 \mathrm{hPa}$ stream function in $70^{\circ}-80^{\circ} \mathrm{N}$ band; e. $850 \mathrm{hPa}$ stream function in $60^{\circ}-70^{\circ} \mathrm{N}$ band;

f. $850 \mathrm{hPa}$ stream function in $50^{\circ}-60^{\circ} \mathrm{N}$ band; 
g. $500 \mathrm{hPa}$ stream function in $70^{\circ}-80^{\circ} \mathrm{N}$ band; h. $500 \mathrm{hPa}$ stream function in $60^{\circ}-70^{\circ} \mathrm{N}$ band;

i. $500 \mathrm{hPa}$ stream function in $50^{\circ}-60^{\circ} \mathrm{N}$ band;

j. $200 \mathrm{hPa}$ stream function in $70^{\circ}-80^{\circ} \mathrm{N}$ band; k. $200 \mathrm{hPa}$ stream function in $60^{\circ}-70^{\circ} \mathrm{N}$ band;

1. $200 \mathrm{hPa}$ stream function in $50^{\circ}-60^{\circ} \mathrm{N}$ band

According to Hoskins' great circle theory, an important application of the wave structure is that the large scale climate variability in the northern hemisphere can be understood from the point of view of the teleconnection. Large scale Rossby wave can transfer the perturbation information along the ray path around the sphere. Thus the North Atlantic Oscillation, the Arctic Oscillation and the oscillation in the north Pacific are likely to be connected through the wave process. Given the perturbation source at the north Atlantic, the signal can propagate northeastward as the form of planetary wave and cross through the Arctic region to the north Pacific. However, the assumption should be further explored with the data analysis and model works.

Acknowledgments. We thank Doctor Yongguang Hu for his constructive suggestion and modification on the manuscript.

\section{References}

1. Rossby, C. G., collaborators: Relation between Variations in the Intensity of the Zonal Circulation of the Atmosphere and the Displacements of the Semi-permanent Centers of Action, J. Mar. Res., (1939) 39-55

2. Thompson, D. W. J., J. M. Wallace: The Arctic Oscillation Signature in the Wintertime Geopotential Height and Temperature Fields, Geophys. Res. Lett., 25, (1998) 1297-1300

3. Donald J. Cavalieri, Sirpa Häkkinen: Arctic Climate and Atmospheric Planetary Waves, Geophys. Res. Lett., 28, (2001) 791-794

4. Yu W., M. Ikeda, Z. Liu, M. Xia: A Dynamic View of Arctic Oscillation, its Teleconnection with NAO and PDO. Proceeding of Chinese-Norwegian Symposium on Polar Research, Shanghai (2001)

5. Kalnay E., Co-authors: The NCEP/NCAR Reanalysis 40-year Project, Bull. Amer. Meteor. Soc., 77, (1996) 437-471

6. Holton, J. R.: An Introduction to Dynamic Meteorology, 3rd edn., Academic Press (1992)

7. Adams, J., Swarztrauber, P., Sweet, R.: Fishpack - A package of Fortran Subprograms for the Solution of Separable Elliptic Partial Differential Equations (1980). Available from http://www.netlib.org/fishpack

8. Trenberth, K. E., Hurrel, J. W.: Decadal Atmosphere-ocean Variations in the Pacific, Clim. Dynamics, 9, (1994) 303-319

9. Cavalieri, K. J., P. Gloersen, C. L. Parkinson, J. C. Comiso, H. J. Zwally: Observed Hemispheric Asymmetry in Global Sea Ice Changes, Science, 272, (1997) 1104-1106

10. Hoskins, B. J., Karoly, D. J.: The Steady Response of a Spherical Atmosphere to Thermal and Orographic Forcing, J. Atmos. Sci., 38, (1981) 1179-1196 